\title{
Dementia-friendly vision
}

Volume 4 Issue 2 - 2015

\section{Introduction}

As a person living with this disease I find it a challenge these days to be able to communicate with the rest of the team. While I appear to be very normal when we have short talks, there are many issues that I struggle with. I have lost the sharpness and quick response needed to be able to interact with you all at your level. It makes it even harder when many of you have very high IQs. With time you will learn that while I may not respond immediately, answers come to me many hours later. Sometimes they never do. When I hear conversations I do not hear the entire sentence but part of it, and in my mind I fill in the blanks. It's weird to know you have many answers in your head, but cannot find a way to retrieve them.

Because of all this, and because we are breaking up into various teams I want to ensure I will have the opportunity to share my visions of what I would like to see. Some of these ideas come from others who have created them before me, and many are my own ideas or a combination of both ideas.

There is no true order and some things may even be duplicated due to my lack of recall. I did have help from others in the editing of this document. Below is my short list of issues as I see them from my introduction statement on June 7th.

\section{Public awareness, education, \& engagement}

In my opinion awareness is the biggest problem. The face behind the disease must change if we are going to get the public engaged. We must show younger people who don't understand that Alzheimer is a disease that affects all ages; it is not just associated with getting older. I know of a 30-year-old and a 29-year-old who have it.

A. The stigma must be eradicated.

B. Companies and communities must treat this like any other disability.

C. State laws needs to change so those who are getting fired can collect the benefits they deserve immediately.

D. Once we have a diagnosis, we should all be entitled to the same level of benefits no matter what our age is.

E. People should be fast-tracked for social security instead of being treated like crooks while they are getting deeper into hardship.

F. First responders need educating, and a system needs to be created that will help identify us without becoming a target for others.

G. We need a way to deal with our guns.

H. Driving laws need to change to remove the licenses of those who are no longer capable, and not to impact those that are still able to drive.

I. Health providers and institutions must change in many ways if we are looking to make it better for those impacted.

J. Need to encourage dementia-friendly communities and business.

$\mathrm{K}$. We must be able to live life to the fullest even though we have the diagnosis.

\author{
Michael Ellenbogen \\ Dementia Action Alliance's (DAA), USA
}

Correspondence: Michael Ellenbogen's, Dementia Action Alliance's (DAA), USA, Email authorellenbogen@gmail.com

Received: October 15, 2015 | Published: November 06, 2015

L. Create work environments in which we can still feel productive without penalty to the employer or the person living with the disease.

M. We must encourage the researcher and provide funding.

N. Trials need to provide more flexibility by using communication technology.

O. Family savings should not be wiped out just because one has dementia.

P. Patients should be made aware of the living wills which should be very different for those with AD. While this is a taboo subject we should have the right to end our life in a dignified way. We must talk about these issues.

\section{Dementia-friendly communities}

My vision of a dementia-friendly community is a bit involved, but if it's implemented it will have a huge impact in many ways. When I think of a dementia-friendly community it refers mostly to those who are in the early to mid stages of the disease. This idea was first started in the UK by my friend Norm McNamara who is living with Lewy Body Dementia.

This community should include first responders, health providers, local businesses, public transportation providers, airports, and the public.

I think the best way to achieve this is to create a system that allows individuals to register with the state, or someone of equal standing, this should include care partners as well as it's important to have emergency info on the caregiver. I would like to see something similar to Medic Alert at a state level. What follows is a brief outline of the Medic Alert system.

MedicAlert ${ }^{\circledR}+$ alzheimer's association safe return ${ }^{\circledR}$ is a 24 -hour nationwide emergency response service for individuals with Alzheimer's or a related dementia who wander or have a medical emergency. We provide 24-hour assistance, no matter when or where the person is reported missing. 
i. If an individual with Alzheimer's or a related dementia wanders and becomes lost, caregivers can call the 24-hour emergency response line $(1.800 .625 .3780)$ to report it.

ii. A community support network will be activated, including local Alzheimer Association chapters and law enforcement agencies. With this service, critical medical information will be provided to emergency responders when needed.

iii. If a citizen or emergency personnel finds the person with dementia, they can call the toll-free number listed on person's Medic Alert + Safe Return ID jewelry. Medic Alert + Safe Return will notify the listed contacts, making sure the person is returned home.

Six in 10 people with dementia will wander and/or get lost. A person with Alzheimer's may not remember their name or address, and can become disoriented, even in familiar places. For people with dementia wandering is dangerous, but there are strategies and services to help prevent it.

The Alzheimer's Association has developed training tools and support programs to prepare law enforcement, EMTs, fire fighters and other first responders when they encounter a person who is wandering.

Anyone who has memory problems and is able to walk is at risk for wandering. Even in the early stages of dementia, a person can become disoriented or confused for a period of time. It's important to plan ahead for this type of situation. Wandering and getting lost can happen during any stage of the disease.

Be on the lookout for the following warning signs:

a. Returns from a regular walk or drive later than usual

b. Tries to fulfill former obligations, such as going to work

c. Tries or wants to "go home", even when at home

d. Is restless, paces or makes repetitive movements

e. Has difficulty locating familiar places like the bathroom, bedroom or dining room

f. Asks the whereabouts of current or past friends and family

g. Acts as if doing a hobby or chore, but nothing gets done (e.g. moves around pots and dirt without actually planting anything)

\section{h. Appears lost in a new or changed environment}

The information on your medical alert bracelet will connect health professionals with your emergency medical information. We provide memberships and services designed to protect you and your loved ones during a medical emergency or time of need.

Medic Alert's medical bracelets, medical IDs, and other medical jewelry have been used to alert responders of the underlying medical conditions a patient may have-such as allergies, anaphylaxes, diabetes, and autism. First responders are trained by Medic Alert staff to recognize all forms of medical IDs, and our services ensure they get your up-to-date medical information, the moment they need it, to make informed decisions about your treatment and care. Medic Alert services and medical IDs are also used to communicate advance directives and can even help those with Alzheimer's or dementia make it home safely during wandering emergencies.

For more information please visit their website: http://www.alz. org/care/alzheimers-dementia-safety.asp

Those who choose to register would wear a bracelet similar to the one above or some type of dog tag on a chain. By registering the pe- ople would be able to take advantage of many benefits. Family would need to register and could be set up when in the clinic for diagnosis as well as info bracelet... ordered and resources given out.

All those registered would be given a unique identification number that will have basic information that could be used in case of emergency. To stop the system being abused or compromised, this information should only be accessible by the relevant people, following a secure procedure and calling a special telephone number and providing the person's ID number. (This would only be accessed by calling a provided number). It may include information like blood type, allergies, drug information, doctors, emergency contacts, and addresses. This system needs to be linked with the 911 systems, and the yellow dot program. When a person calls the fire department the address should be flagged immediately when it comes up as a person with dementia living in the residence they are being dispatched to. This is important for many reasons.

A person with dementia may panic in this situation and may not know how to respond to the emergency conditions. They may be much worse than a child in some cases, and just curl up in a corner in fear and just stay there. They may not even speak out when people are calling their name. They may have even started the fire and are scared. They could be combative and the firefighters need to know how to deal with that situation. There are many other reasons why the firemen need to be aware before arriving.

If we ever have some kind of a natural disaster or need to evacuate for some emergency this system will be a major asset, especially for those who may be at home on their own. By being registered this will insure a much better outcome for those who may not be able to think for themselves. Many of these people would not leave with just a simple call and they may not even understand what is said in robo-call type alerts.

If the police are called that should also be flagged immediately. It could be the person with dementia calling in, and not able to articulate the problem. It could even be a false alarm because they are scared when there is really no threat. Sometimes people with dementia have been known to make serious accusations of being threatened by their spouse with a gun, which has led to spouses being locked up for days because the system was not aware of the person's dementia. Again, if members of the emergency services are coming to a house where a person with dementia resides, they need to treat threats in a completely different way otherwise it can escalate and even become deadly.

\section{Issues with police: weapons \& driving}

While I am on the subject of issues with police there is a document which I shared with the chief of police a few years ago. While some changes are being implemented in some parts of the US, I am not sure they are being addressed in PA. I tried to reach out to my local police department and training facilities, but was just blown off. One of the biggest and most serious issues that I feel needs to be addresses is that of weapons. I came very close to taking my life, and even told a police officer on the telephone, but he refused to do anything. I just wonder how many other people pleaded for help and ended up killing themselves because nobody answered their cry for help. This is unacceptable.

Sometimes people with dementia get confused or feel threatened and may make accusations that could land someone else in jail. Be prepared to deal with cases like this. They need to be handled very differently from someone without dementia. Some would say like a mental illness. They believe what they are saying is fact. 
We require a place to store or remove guns from a home when needed-I came up with a simple way that this could be accomplished without too much impact on the police. A gun safety device can be used to secure the guns in the person's home, and the key can be given to someone responsible. There were other suggestions made.

If someone with Alzheimer's is stopped for a sobriety test they may fail because they have trouble following instructions or poor gait. They may also be much slower with their responses, and may even give you a blind stare because they are confused. They may not be able to follow complex directions. Directions need to be broken down into steps.

I know we want to make the roads safe so we need better testing methods for Alzheimer's patients who drive. Alzheimer's patients can sometimes become very aggressive and defensive during an argument, they can even become threatening. This is the wrong time to try to remove them from their home. They need to be calmed down first; otherwise it can become a disaster for that person, because many will not understand what is going on.

Be prepared to deal with people who may seek help when they are lost. We can get lost while driving; this does not mean we cannot drive. These two issues are often confused by many.

The car should also have some sort of identification mark. It could be tied-in with the yellow dot system; however, I am concerned that we may become a target because of that. We are much more gullible because of this disease and that could be a very serious issue. I was someone who always kept all those scammers at a far distance, and now I am starting to fall prey to some and think it will only get worse as time goes on and I get worse. It could be on a driver's license, like a donor or class B license. It could be a code that is not obvious to all.

\section{Universal symbol: the purple angel}

There is a common logo that is slowly becoming the internationally known symbol for those living with dementia and I think we should use it. It is called the Purple Angel.

To be used on all websites and dementia patients information and hospitals.

For stores and businesses to show they know and have been educated. This was created by Norm McNamara and is starting to get a lot of recognition. In fact it is now going to be used in some US hospitals as an indicator that the person has cognitive issues; they hang it on the door of the hospital room of the patient. I recommend that we adopt this symbol for all programs connected to dementia-friendly communities.

\section{Dementia-friendly hospitals}

While I am speaking about hospitals, below is a list of issues that I have been working on with a local hospital in hopes of starting the first dementia-friendly hospital in PA. I was trying to build a training program with the Alzheimer's Association along with a question and answer session with people like me who are living with the disease. Below is the list I have shared with them. Some hospitals are actually doing a quick cognitive test by asking 3 words upon registering to see if there may be a concern even if the person does not have a diagnosis. I would expect that all hospitals would educate staff on the issues, for instance we can easily get lost while trying to find a department as an outpatient.

At registration, identify a person that can and will be able to be involved in all decision-making, along with the patient. At registration, identify a person that will be given full access to all records on behalf of the patient. Patients bring in a list of current medications. If for some reason you must change the drug or dosage for any reason, the issue should be addressed with the patient and caregiver to ensure there are no issues (even if it's as simple as converting to a generic). Sometimes patients cannot take another form of the same drug-ask them.

Example: My doctor switched me to Galantamine rather than Aricept because of side effects. In the hospital, they substituted Aricept. (My wife had Galantamine with her, but of course it is a big deal that you should not take your own meds.)

A special ID bracelet should be placed on this type of individual so the staff is alerted that this patient has some form of dementia. This will help them if the patient is acting confused or wandering or just needs a little extra help or explanation. It may also mean that the patient isn't great at making good decisions. If you need a color, purple is perfect.

Example: I needed a Fleet's enema pre-op. The nurse asked if she should give it to me or if I wanted to use it myself in the bathroom. Of course, I offered to do it myself. I found I had difficulty once I got in the bathroom by myself; a bad decision on my part. The nurse should have not given me the option. (We do not want to appear stupid or show our flaws so we may do something to show we are still capable when we may not be). I know they always ask the patient for their full name and birthdate - that may be hard at times for us. I can become confused on a good day, in the hospital it can be worse because of pain medication or being awakened suddenly or the stress of just being out of our routine. Maybe another way can be figured out. (Before a name tag is placed on a dementia patient it may require 3 or 4 staff individuals to ask the patient for that information and each must identify the same information before the ID is placed. This will insure the wrong tag is not placed on the patient. Use the verbal ask on critical things like surgery and drugs given the first time the nurse may see the patient)

There are special things one needs to know about using Anesthesia. Anesthetic agents are a cause for concern in AD pathogenesis. Luckily, the field of Anesthesiology has addressed these concerns in an excellent and honest manner. I would defer to their consensus statement:

http://www.anesthesia-analgesia.org/content/108/5/1627.full

http://www.mc.vanderbilt.edu/

The bottom line seems to be to avoid isoflorane. Do not always consider a patient being confused as a part of the dementia, but it could be much worse due to the drugs they are on. When I was on pain killers my wife could not even get a response from me that made much sense, and she knows what's normal for me. A real concern exists on what type of drugs the patient may receive for Anesthesia. Pain killers will also have a much greater impact on this type of person.

While ordering food from a menu is simple, it is very overwhelming for me to keep track of things and what items may even go together, or are even needed. I will probably need help with this task.

Don't assume we can figure out how to use items in the room like TV, Phone, call button, and anything else. Please point them out and provide a simple explanation on their use.

Aides should not be the first point of contact. I am not always good at explaining what I need and the aide was not always good at interpreting what I was trying to say. Aides are okay for follow-up or to help with food menus. Again this is why training on all levels is so critical. 
When asking a question, give them a minute or two to answer without going on to some other question. You could even ask them to think about it and come back in 5-10minutes, no longer. This is very subjective depending on the person. We often need a few minutes to gather our thoughts. We might even answer a question right away and then realize a few minutes later that that wasn't what you asked.

Somehow you need to insure the patient response is really correctly given - they sometimes give an answer just to not appear stupid or show they did not understand. Maybe some visual aid or clues can be given along with the verbal depending on the stage the patient is in.

Try to keep items and things in the room in the same place once they determine the best location for them. I personally feel these patients should be kept a bit longer than the average person, for observation. This would just be to make certain there are no issues at time of release.

Offer a pen and paper to keep in the room. Tell them to write down questions they want to remember to ask when the nurse comes in the room. Keep in mind many patients with dementia can no longer spell correctly and may use the wrong context for words.

This is the wristband that will be implemented to all patients with dementia at Brooksville Regional Hospital, along with this square magnet to be place on the outside of the patient's room on the doorframe. Before any of these wristbands will be used, training seminars from the Alzheimer's Association will held for all of the hospital staff members. Training should start in about a month. This is a major step forward in maintaining the safety of all dementia patients during hospital stays.

The hospital loves the purple angel logo, We went through three different band designs before this. The problem being that purple is also the national color for DNR. What I love about it the most is that it's for "all dementias," which is what we truly need in the hospitals.

\section{Dementia-friendly businesses}

Moving on to dementia-friendly businesses; I envision that businesses take a 7 or 8 hour course provided for free by the Alzheimer's Association and others, to make them aware of the issues that people with dementia deal with, and what they may need help with. On completion of the course they will get a sticker that they can place in their place of business that says Dementia-Aware with a picture of the logo. By doing this we will be creating awareness, and educating many on how to make it easier for us to still function as members of society; something that is not always easy when you are an adult who is slowly becoming a child again.

Some of the issues may be

- Feeling panic in a large store when becoming separated from the person they came with.

- Being asked a question and not being able to respond, or even giving the wrong information.

- Having trouble locating items in stores.

- No longer being able to calculate how much they have spent or can spend if they have a budget.

- Getting lost, losing sense of direction, or not being able to locate the car in the parking lot.

- It would be nice to get assistance when there are similar products to choose from, because I can no longer do comparison shopping based on price, or if an item in the same category is on sale.
Not everyone will easily display, or even be willing to wear the bracelet or dog tag because of the stigma surrounding this disease. Only when this changes will people feel more comfortable about sharing their diagnosis with others.

Even though we are living with $\mathrm{AD}$ we should be encouraged to live life to the fullest. We need to keep our minds engaged. We should be able to work, and to still do high level functioning jobs, and the company not be penalized, and the person with the disease should not be impacted by SS because they are working. As volunteers I would expect that our transportation expenses be paid for, and maybe even lunch. This will have a positive impact on the people with the disease and be of great benefit to a company that can utilize the person. Some do not want jobs like pushing hospital beds around, or doing simple tasks when we have a high function skill set.

The state can help AD people to live life to the fullest in many ways. For those that are still driving they should be given a disabled sign for their car. It helps me in many ways such as finding my car when I park in a strange place or large lots. For those that are not driving, allow us the same opportunity as seniors. This will help us get around much easier. For suburban areas allow us access to the transportation for the disabled at the discounted rates.

The state can offer free access to national parks, fishing and boating for a small size water craft for the person living with the disease and a caregiver since in many cases they will need someone to take them. All of this can be centered on having the bracelet which will simplify the process and minimize any costs.

Keep in mind you need to make it simple for these people because they will most likely not be able to fill out many of the forms needed to qualify. I am sure there are many other things that can be made available. Writing skills can be impacted hindering communicating. An idea would be to forward our unedited letters to schools to be used as a part of the English classes; the students would edit the letter and send it back so we can send it. It would also be great if we could take college courses for free with the idea that we are not getting a degree or credits.

When it comes to purchasing tickets for travelling on trains etc. staff need to be aware that we may need help. We may not be able to check in at the airport unaided. We should not be penalized for not being able to take advantage of online offers because we cannot use computers. We may need to be taken to a gate or to a temporary room until our flight or train is ready (this does not mean we need to be ferried about in a wheelchair!)

For further information about dementia friendly communities:

\section{Dementia-friendly Communities:}

- Dementia Without Walls project and report (Joseph Roundtree Foundation,

- UK): http://www.jrf.org.uk/work/workarea/dementia-without-walls

- UK Department of Health Dementia Challenge: questions about dementia-friendly communities and responses from readers:

- http://dementiachallenge.dh.gov.uk/2012/05/28/dementiafriendlyquestion/

- UK Alzheimer's Society Dementia-friendly communities programme:

- http://alzheimers.org.uk/site/scripts/documents_info.php?documentID $=1843$ 
I would like to see a simple pamphlet be put together for those who are living with the disease covering all the benefits available to us with $\mathrm{AD}$. It must be simple to understand, short and to the point. The procedure should include all of the resources available and where one should turn. Today one has no clue and they do not know what is available. This should be handed out with a diagnosis from your doctor.

Laws need to change so those who are getting fired can collect the benefits they deserve. Let's stop burdening the social security system. Because there is no clear test for the diagnosis of YOAD, many diagnoses are delayed. Many people are terminated from jobs, and are unable to collect their long-term disability insurance, because of the two-year law. Most diagnoses occur much later, as in my case. I paid a lot of money into a long-term health disability plan in my company and I lost it all because of the law. I now get less than a third of what I would have been entitled to, and no medical coverage which I would also have had, all because of a law that does not work for individuals with this disease. Changes must be put in place until we have better tests available. If someone is terminated for non-performance and they have been diagnosed with dementia at a later time, they should have the right to go back at least six years to prove their case. Companies should not get a free pass because we all pay for this injustice. The two year law is a failure for people like me with dementia.

I was terminated from my job before I got a diagnosis which took another 6 years. Now I am forced to rely on government disability. Alzheimer's is a sickness. This is a disease, and the people who have it should be treated that way. Companies need to treat $\mathrm{AD}$ like any other disability. The following comments were put together from a person who works in HR.

Tell your story to HR Management. What kind of company do they want to be? How will they protect their human resource that has dementia-and be good risk managers by taking appropriate action to minimize the risk of litigation for wrongful termination under ADA? What are the costs of unrecognized dementia in employees i.e., lost productivity, errors, quality, odd/unexplained behavior, a decline in management skills leading to more of the above? What are the State percentages? Give examples-If they are a company of 1,000 employees that equates to $\mathrm{xx}$ employees who will have early onset dementia-can they afford to be blind to the problems these individuals will cost the organization? Alzheimer's is not all about the needs of the caregiver. Little to no attention is given to the INDIVIDUAL WITH DEMENTIA. If the company has a PEP program (Personal Employee Program that typically provides 8 to 12 sessions of counseling when an employee suffers from personal problems (divorce, runaway kids, elderly care, etc.) why not have a Dementia Hotline/Exploration. Why not help people self-diagnose early and assist them to seek a medical diagnosis, so TOGETHER the employee and company can make a plan for them to ultimately exit from the company with dignity example: an employee is still skilled, but may need to move from having the responsibility of being a manager to becoming an individual contributor. Why wait to FIRE someone for non-performance, when you could continue to employ the person until the day comes where there is no job which matches the employee's skills. A diagnosis of dementia IS protected under ADA. Why wait to be sued by an employee who was unfairly terminated because of his disability. Why not be proactive and humane, keep the person off unemployment; mitigate your exposure to litigation. Such a small cost to set up a program to assist and empower employees to work TOGETHER with them, give them dignity and determine together when it is time to go. Help them transition to retirement with disability; unemployment; assistance from the Alz Association.

\section{Financial issues \& necessary system change}

Younger-onset Alzheimer's, also known as early-onset Alzheimer's, generally refers to those who are affected by the disease before the age of 65 , usually in their 40 s or $50 \mathrm{~s}$. Because of their younger age and healthy appearance, doctors often attribute symptoms of Alzheimer's to depression or stress, resulting in delayed diagnosis. These symptoms, such as challenges with short-term memory, impaired judgment and difficulty making decisions, eventually progress to a point where they affect workplace performance, and ultimately, jeopardize employment. Many individuals living with younger-onset Alzheimer's are in their prime earning years and supporting loved ones at home. The loss of income and access to employer-sponsored health benefits can be devastating.

This document reflects State and Federal issues that may not be working. My goal is that if the existing jurisdiction responsible is not able to enhance the process, the other will step in and fill in the gaps so people are not impacted. It is my hope that they can work together to fix the weaknesses in the system that may have been overlooked.

To help address their financial need, many individuals with younger-onset Alzheimer's rely on Social Security Disability Income (SSDI), or Supplemental Security Income (SSI). In March 2010, the Social Security Administration (SSA) added early-onset Alzheimer's to its Compassionate Allowance Initiative, which expedites the disability determination process and serves as a trigger to begin the two-year wait for Medicare benefits for those under the age of 65 . Family members (e.g. spouses and minor children) may also be eligible for benefits based on the applicant's work record. This addition by SSA has been a huge relief for individuals and families dealing with Alzheimer's.

Many are treated like they are crooks when they apply for Social Security Disability. It creates an added burden on the family and the patient. People say that the Compassionate Allowance act will help people, but it did not help me, and many keep saying that it works. The following story is from an ongoing case. This program may be better but the people who run the programs are clueless in many ways on what a person with $\mathrm{AD}$ can or cannot do. This person is not only struggling financially, but has no one to look out for them. I cannot even imagine the hell they must be going through because it would take me forever to complete the same forms.

\section{Hi Michael}

It's so nice of you to think of me. I wanted to add that the reason I was turned down on the first application and reconsideration was because I filled out the RFC form myself (I lived alone at the time and it was a necessity) and not for lack of medical evidence. My son now lives with me but only minimally supervises me and does the driving. An examiner at Social Security took it upon himself to send out an investigative unit because he felt I must be faking Alz even though in the course of the application and reconsideration, I saw 5 doctors, 4 of whom thought I had Alz disease and $1 \mathrm{CE}$ examiner who thought it was possible but hesitated because I still have average intelligence (my IQ was in the 140s when I was in graduate school and now around 100, which I think this is an alarming decline). This SAA evaluator then proceeded to imply that all the doctors I saw were fooled. He even sent out an investigative unit to actually videotape me without my knowledge (following me to one my CE appointment one day and sending undercover police officers to my home the following day). I don't remember the investigators coming to my home and didn't see them at the hospital (obviously quite good at the stealth part). At the hospital, the doctor walked me out to the lobby because he 
was afraid I would get lost said a few minutes later I "disappeared (I got my ride, of course)." They went back to the doctor looking for me, and he apparently was very concerned I had actually gotten lost in the hospital. At my house, they said I walked slow to answer the door but I didn't limp (???) and was polite and had my hair combed (implying I was not disabled based on my outward appearance and probably less than 30seconds of conversation). The evaluator felt that anyone who could describe their symptoms on an application, write mostly coherently, (though always needing multiple edits, spell check, and entailing a lot of repetitiveness) answer the door, use a phone, live alone, or drive in the early stages had to be faking it regardless of MRI, neurological tests, etc., that clearly gave me a diagnosis of EOAD. Long-winded, I'm sorry. I'm still feeling kind of abused and outraged.As for now, my lawyer thinks he can get me a hearing OTR and I'm hoping for that and a favorable decision If not, it will be another $12-15$ months before I have a hearing date, this because the SSA evaluator apparently does not understand that early-stage Alzheimer's is not immediately visible on the surface. In the meantime, I am now in the process of selling my home to live with my adult son as we can no longer afford the upkeep (this is a modest home - but now far above my means).

I'm very lucky that my son is living with me to help, but it means I do not qualify for Medicaid because his income is now considered my income and puts us just above the income limit. He can't put me on his insurance as I don't qualify as a dependent because of my small LTD policy, which in turn needs to be repaid to the insurance company if I do get SSDI. I've gone from a single, self-supporting middle class woman, to lower middle class, now to poverty level in the course of about 4years. Without my son's help, I'm probably within 3months of living on the street. At the same time, I'm suddenly placing a tremendous burden on him and fouling up his goals in life.

Another note: I find it ironic that my neurologist tells me to exercise vigorously, take care of my health, and socialize as much as possible in order to function longer whereas I sense the government is telling me that I'm not eligible for disability insurance (despite working since age 13 and paying into the system for years) unless I give up, lie in bed, and wait to die.

It would be great if the Alz Assoc could find a way to educate the SSA evaluators on what Alzheimer's disease looks like in younger people in the early stages so that other people don't go through what I'm going through now.It would also be great if they could lobby for earlier Medicare benefits (rather than the 2 year wait after SSDI) for all disabilities that are only going to deteriorate.

\section{Awareness is the biggest problem}

Awareness of YOAD will change the public perception of who gets Alzheimer's-young people. People who are under 30 get it. Use commercials, billboards or posters in key places to get the word out. The face behind the disease must change if we are going to get the public engaged. We must show younger people because most don't understand that Alzheimer is a disease not just a result of aging.

Awareness of outcomes for AD-Currently people who have Alzheimer's cannot be cured. There is no way to slow the progression of the disease, and most die within 4 to 8 years of diagnosis. While these two statements are strong I feel this is what it's going to take to reach younger generations and others to jump in and help. We cannot beat around the bush; the public needs to know that this is a horrific way to die. Death by Alzheimer's is slow and painful not to mention the impact it has on the family. Places like the Alzheimer's Association and others need to open with all the facts about the disease so people are prepared.
Remove the negative stigma associated with the disease. Too many people are ashamed to let others know that they have this disease. They act like they did something wrong to get it. Now is the time to join me, come out of the closet, hold your head up and be proud in making a difference in how we are looked upon by ourselves, and others. WE need to show that we are still capable of doing some things at our own pace.

Driving laws need to change to remove the licenses of those that are no longer capable, while not impacting those that are still able to drive. It should be based on the person's true driving experience and ability, and not on perceptions or fears. It should have nothing to do with getting lost; GPS tracking devices can help us if that is a concern. Many people have the misconception that if a person with AD is in an accident the insurance company will not pay for the claim, or may even sue them. While there are many tests available to test one's driving, many are not fair to a person living with $\mathrm{AD}$. In fact if the average person was given the same test they may even fail. Better tests that deal the individual living with the disease are needed and all must be able to test this test. Some of the cognitive tests do not correlate to driving ability, but to failing and singling out people with AD. That is completely unfair. For example I fail the Trail-Making Test, Part B and I still drive very good. The testing should be free or paid by insurance. These tests can cost around $\$ 300-\$ 350$, and provide annually. Every 2-3months we should drive with a spouse or other person who understands us to see how well we drive. That should be a regular part of our future lives, and they should be the ones to tell us when they feel it is time to give up driving. I am not saying that people with AD should not eventually stop driving, but it should be done for the right reasons - that they will become a danger to them or someone else. What we need to focus on are the real problems of driving, and not the side issues related to them. We must embrace new ways to deal with people with $\mathrm{AD}$ and find new opportunities and technologies to use to our advantage so we can enhance the lives of those suffering with this disease, and so they can continue to lead a normal life for as long as possible. Do not fall into the one-size-fits-all trap because all those living with $\mathrm{AD}$ are different from each other and we must figure out a way to make everyone feel safe including those living with the disease. We are still human beings. My biggest fear is that one day I will have an accident and my license will be taken away. It may not have anything to do with my Alzheimer's, but it will be perceived that way. I have had 3 to 4 car accidents in my lifetime, some being my fault while most were others. We all have them.

As a person living with $\mathrm{AD}$ I seem to notice much more. I see many people run through lights, not use turn signals or come to a complete stop at the stop sign. I see people cut others off or shift in to other's lanes without paying attention. All I can think is that if people saw me do any of these things they would want to take my driver's license away, yet all of these folks are normal and they just get a free pass. Why?

Once we have a diagnosis, we should all be entitled to the same level of benefits no matter what our age is. One should not be impacted by other laws that were not designed or intended for those living with this type of disease. There are many state and federal programs that limit us from being able to contribute to or benefits we are not entitled to because of our age. Family savings should not be wiped out just because one has dementia. A family should have a cap on what they must payout. Why should the surviving spouse be left penniless because their partner was sick? Is it enough that most of us have already had to deal with financial hardship we were not accustom to?

Pa. Caregiver Support Program (care recipient/household income must be @ 200\% of poverty or below for max. reimbursement. 


\section{Below are just of a few of the ways this disease is cos- ting me more money than ever}

I once did most things around the house and now I have to rely on others and the cost is adding up very quickly. Many things are becoming neglected which will have a greater cost in the long run. I used to be good at comparison shopping and now I no longer do it because I cannot recall the price so I can compare. This has such a huge impact from food, gas, utilities and everyday items.

Furthermore, under the Patient Protection and Affordable Care Act (PPACA), individuals with a pre-existing condition receiving SSDI can join high-risk insurance pools 3 and receive immediate health insurance coverage while they wait for Medicare benefits to become available. This has been particularly helpful for those who are unable to find affordable health insurance because of their Alzheimer's diagnosis. The program will end in 2014 , at which time individuals can purchase health insurance through their state-based insurance exchange or qualify for Medicaid under its expanded criteria. Pennsylvania has yet to decide whether or not it wants to participate in the Medicaid expansion, which according to one estimate, will cost the state 1.4 percent more than current spend to reduce the number of uninsured adults by over $40 \%$.

In addition to the cost of care, Alzheimer's imposes an immense burden on families. Last year, there were an estimated 664,384 unpaid caregivers in Pennsylvania, providing 756,600,213hours of unpaid care valued at over $\$ 9$ billion. Unfortunately, the physical toll of caring for Alzheimer's also resulted in over \$427million in additional healthcare costs to unpaid caregivers in your state. To assist those who care for people with Alzheimer's in Pennsylvania, the state offers the Pennsylvania Caregiver Support Program. Preference is given to caregivers of care recipients who are 60years or older, but eligibility was recently expanded to include care recipients who are 18years or older. All care recipients must demonstrate functional limitation and financial need.

Regrettably, age is still a barrier to other support programs for individuals with younger-onset Alzheimer's and their caregivers. All caregiver support programs that receive funding under Title III of the Older Americans Act require care recipients to be at least 60years or older. Likewise, Pennsylvania's Medicaid 60+ waiver and aging block grants are only available to those who are at least 60years old. Restricting eligibility by age, rather than diagnosis, forces many families affected by younger-onset Alzheimer's to exhaust their own resources and put their own health and financial security at risk.

Health providers and institutions must change in many ways to make it better for those impacted. Physician education-Doctors need to be better educated, and need to commit to a more timely diagnosis so that patients can collect the benefits they deserve and are entitled. Doctors should not act like our lives are over. Once a diagnosis is made it should automatically trigger a referral to a psychologist or psychiatrist so the person can learn to deal with the devastating news. Many people are in denial and waste that last few years not knowing what to do. Instead they should be living life to the fullest. Make the memories. We must be encouraged to make living wills and put our financials in order quickly since our minds are going. We have no time to delay. Encourage participation in medical trails and offer frequent checkups.

Living wills should be very different for those with AD. While this is a taboo subject we should have the right to end our life in a dignified way. We must talk about these issues. We must encourage research and provide funding. In order to eradicate this disease we need to find more sources of funding and redistribute current government funding to bring Alzheimer's to a level comparable to other disease research. Trials need to provide more flexibility by using technology. Many are unable to participate due to lack of flexibility. Some people do not participate in clinical trials because they feel it will not help them. They need to know that it's not about them but what they do can help someone in their family should they get the disease. Since a cure may be long in coming, it would also be nice to see more funding provided to investigate treatment methods to maintain independent function longer. The drug companies have taken the stage and it's all about what increases their profit and not necessarily about what will help the patients.

Make government grant programs free, fair and balanced-Some researchers using government research grants are discriminating by age and minorities because of rules being set forth by both the provider and the receiving researcher. This will prevent the formation of an accurate picture of this disease. For example, black people are twice as likely to get Alzheimer's. Why?

Eliminate the term Caregiver - Come up with a new term for the word caregiver when used for people in the following stages.

- Very mild decline

- Mild decline

- Moderate decline

We find it very demeaning and do not like being treated like a child. Help us where we are weak, but don't give up on us just because we have now been labeled with Alzheimer's.

We need away a way to break down many of the silos and built a coalition of companies and sites to work as one. Leaders Engaged on Alzheimer's Disease (LEAD) is a diverse and growing national coalition of 58 member organizations including patient advocacy and voluntary health non-profits, philanthropies and foundations, trade and professional associations, academic research and clinical institutions, and biotechnology and pharmaceutical companies. The only sad part is the Alzheimer's National has not joined due to not being able to set politics aside.

\section{http://www.leadcoalition.org/}

This is all part of the problem - a lack of willingness to work together. I am not sure what the state can do here but we need to find a way to encourage others to work in harmony for the greater good of what we all seem to claim. We are doing this for dementia. Sometimes I really wonder and I think it just a business for these folks.

I know I have made many recommendations around the use of the Alzheimer Association as part of this document. Because of that I want to give full disclosure. I was a past ESAG member and I am currently still an ambassador for them. For those who know me they would tell you I am not influenced by others and my dedication is to those impacted by the disease. With that being said I do feel they deserve a lot of credit for what they have accomplished in the last 30 or more years. They take a lot of heat for some issue that are out of their control due to some high level expectation of the public.

On the other hand I do not want you to think that they have all the answers because I and many others realize that they do not do justice for many like me who are dealing with the disease. They focus on the caregiver and not us. Part of the problem in my eyes is the lack of a business mind across the board, and lack of a CEO approach to business. Because of that scenario there is much inconsistency in the 
organization and much time is lost in understanding our needs and minds. That all leads to very slow response or lack of response to the very services they think are great. They have this internal mindset that everything has to be done a specific way and that is always the right way, yet the people are not given the tools. The sad truth- it is not and I have worked on changing some of that and I can assure you it's not an easy task. I encourage that we continue to work with them but at the same time we need to demand change and at a much faster pace.

I am sharing this with you in hope that, as you do your planning, you take my findings in to account when making recommendations to others. We must treat all people who are suffering from dementia, regardless of stage, with the highest level of respect all the way through to the end. While this may not apply to all, it would appear that many who are even in stage seven are still able to communicate in some way.

\section{Living life with alzheimer's disease}

Below are some articles I have written in the past, you may learn how someone with $\mathrm{AD}$ is dealing with this disease. These are my favorite that I feel people have been able to learn and see another side that they did not know before.

I have worked on this for about five months, and recently I shared the email below with many sites related to AD for feedback. Most of those who had reached out to me were able to support my findings. The bottom line is that while most of us have limited thinking capacity many are able to communicate; we just have to find a way that suits the individual. I received a lot of feedback. My biggest concern is that most people are clueless, and assume that we cannot understand what they are saying about us; many say cruel things. Just try to imagine for a minute what it would be like to hear what others may say or do to you, and you are never given an opportunity to defend or express yourself. That is what is happening to most of these folks.

We must find a better way to educate caregivers, health professionals, and all those working with people living with this disease. The biggest problem I see is that everything is time-based because of the costs. This view will not work for people. It will also take special training, and the need to break with our normal habits of communicating. If we are going to be able to reach out to them, we need to change. We are still human beings and we deserve to be treated in a respectful and dignified manner.

My name is Michael Ellenbogen and I have been living with AD much longer than most people who have had this devastating disease. I am in need of your help to prove a point. Let me explain.

I have learned that as we progress with Alzheimer's/dementia, we lose our brain functioning and can no longer think. I am starting to believe that this is not true.

It has now happened to me on multiple occasions where I was asked a question, and I am able to formulate the answer in my mind, yet I found myself unable to verbalize it. Sometimes my mouth may move but nothing comes out. It was the weirdest thing, and I could not understand why it was happening to me. I was aware of what was going on, but could do nothing.

Since that time I have asked 18 other people with some type of dementia, and of them 16 had similar experiences. Two of them said they had not. This makes me think that as this disease progresses our brain may still be functioning, yet it is unable to communicate with the rest of the body, allowing it to have less control than it would normally have. I truly believe I am on to something, and was curious as to how I can try to prove this theory.
Let me give you an example. About three years ago I met the daughter of a man with AD. He was no longer communicating with her because, she was sure, he could no longer commutate at all. Someone suggested she ask a question, and keep totally silent for at least two minutes after. About a minute and a half later he finally responded to her question. From that time on she realized what she had to do and was thankful for that advice.

I don't want you to think it's going to be that easy; it will take a lot of work, patience and persistence on your part. Here is what I would like others to try for someone who is in the late stages of Alzheimer's. First of all take the person to a very quiet room; it should not have any kind of background noise even from things like an air-conditioner blowing. Those noises are real problems for me, and would assume it will be a bigger issue for them. Such noises really have an impact on my ability to process and focus. You should also do this at a time of day that they are not tired. It becomes very challenging for us to try to focus and listen to what others say. It really becomes tiring, and we get burned out quickly.

When you start to speak to the person use short sentences, and pause in between them so they have time to process what you are saying. That is very important. Tell them that you think you have found a way to communicate with them. Tell them you are going to look at them closely for some sort of sign. It could be an eye movement, maybe looking to the right or left or down or up. It could be a smile. It could be a finger moving or a fist being made. It may even be them sticking their tongue out. I would start by focusing on parts of the body that may still show signs of control. You must become a detective and keep looking at various body parts for some sign. It may not happen the first time or even a second time. It may never happen and I could be wrong. But if I am right just think of the benefits that will come out of this for you and your love one. Reassure them that you will continue to look for a signal and they should keep trying the best they can at their speed. Ask them a simple question like "do you love me? If yes lift your finger or lower your finger". Again you will need to keep quiet, and observe for at least two minutes. Keep doing this and try this with different parts of the body. They may not have control over certain parts, and that may be an issue. If you do see something make sure you point that out to them and ask them to do it again to insure they really are responding. If this turns out to work find a way to use that same body part to get yes or no responses from the person. Keep in mind that this may not always work and you may need to be creative. Maybe just keep the finger raised longer if they mean no, or tap it twice etc., but that may be too much to ask.

Also keep in mind if the person has not had any real dialog with someone for a long time this would also take more time. No matter what do not become discouraged, try this at least three different times on different days. Like I said this may never work and I have it wrong.

If this does work please reply to this site with your contact information so I can speak to you. If this works for a few it makes me believe that we need to treat these folks completely different to the way society treats them today. This will change so much about what people really believe is happening to our minds.

\section{The realities of alzheimer's and overcoming stigma}

Alzheimer's disease and other forms of dementia affect more than 35 million people worldwide today. An astonishing fact that today someone in the world develops dementia every 4seconds. By the middle of the century more than 115 million people will be affected by the disease if we do nothing. 
My name is Michael Ellenbogen, and I am living with Alzheimer's and trying to make a difference. I was previously a high-level manager in the telecommunication industry. In 2008, I was diagnosed with younger-onset Alzheimer's disease (YOAD) after struggling to get a diagnosis since my first symptoms at age 39. Losing my job and not being able to work had a huge impact on my life as I was a workaholic. I am now an Alzheimer's advocate and a spokesperson for the Alzheimer's Association (U.S.) as a member of its national 2012 Early-Stage Advisory Group.

I am so frustrated, because no one realizes how seriously disabled I $\mathrm{am}$. If I had a loss of limb or some other visual ailment, it would make people realize. I don't want them to feel sorry for me or pity me, just want to be understood. So many people say you do not seem to have Alzheimer's, and that frustrates me. Let me tell you what it's like to live with this debilitating and progressive disease.

Imagine for one minute that your friend, relative or family member has Alzheimer's and has to deal with the following issues. When I go shopping and look at items, most of them never really register in my mind, even though I see it clearly. I have trouble making decisions, because I question whether I am making the right one. I can no longer enjoy my favorite hobbies, because it requires processing skills that I no longer have. I went from being a gadget person, to now being threatened by technology that I no longer can use. This is what I deal with and so much more.

I go to a happy affair only to be tortured by the noise and surrounding conversations, because of the loudness that cannot be filtered out. If people try to speak with me in a public setting where there are many other conversations, I just don't understand what they are saying. This is because all of the people speaking come in at the same volume level. All the words run together, and it sounds like a foreign language.

I went from being extremely proactive to becoming much less active and motivated. I leave things around the house and don't put them away, because I don't know where they go or feel I may not know where to retrieve them again. One moment I am nice and another I may fly off the handle. I can no longer write or speak like I used to. My friends slowly become distant and usually speak to my wife. I do realize this.

I worry every day about the challenges ahead. Or even worse, I am losing my mind and see it happening, but I cannot do anything to change the course. People always say "if I can do anything just let me know." If I take them up on that offer, they back out of their commitments. I have become extremely surprised by the lack of public commitment to my pleas for support of Alzheimer's disease. While some may be sympathetic in the moment, there appears to be little follow-through. This is very upsetting, because I feel as though it affects me personally as well as the millions of others living with the disease. I was always there for others when they needed it and now I feel alone.

While many people just coast through the day, I have to use $110 \%$ of my processing skills to do most things, which increases the stress and frustration. The worst part about this disease is knowing that I am doing all these things wrong and have no way to control or stop it, and it's only getting worse as the days go by. I used to save lots of money by doing so many things around the house. Now I lost the drive, determination and skills needed to do those things. Many times I hurt myself trying or make it worse.

I cannot begin to explain how it tears me up inside to see my spouse struggling to do the things that I once was capable of doing and know I cannot do a thing to help. I realize that one day I may no longer be able to drive and this devastates me. I see my wife becoming stres- sed, depressed and overwhelmed, but caregivers know it will only continue to get worse. Sadly, they keep telling themselves that they can do it all even when we know they will need help.

I, the patient, see it definitely. My wife is on the road to hell, and she does not even realize it yet, because she is so busy trying to block it all out. The worst part about all this is, I have not even reached the worst stage. That scares the hell out of me.

I have been so surprised by the stigma associated with this disease. It comes at you from all angles. People think they knew what Alzheimer's is, but they don't. I see this not only from people living with dementia but many media health correspondents, physicians and organizations that are geared to helping those deal with the disease. I have learned that I do not want to share my diagnosis with people I meet until they get to know me. If I was to tell them upfront, I would be treated so differently, which I have learned. I kind of see this disease like HIV use to be. The people who have it are so afraid to let others know, including family. I do not get it. We did nothing wrong to get this disease, and we need to speak up to let our voice be heard. We did nothing and no one should be ashamed of having it. I feel so much better when I share it with others than when I try to hide it.

Because of my frustration with existing environment for people with dementia, I realized change was need. I decided to use my few skills left to advocate. I have spent some of my last few years being on television, radio, newspapers, many blogs and working with many politicians. I also had an opportunity to speak at all of the public sessions to develop the first U.S. National Alzheimer's Plan, all this on my own. But that was not enough, because I ran into so many people who just did not want to get involved. I am now a volunteer for the national Alzheimer's Association Early-Stage Advisory Group. If there is something I want you to walk away with it's that you can make a difference, but it will take persistence. Write a letter to your public official or reach out to local support organizations to create needed programs and services. Your voice and your story are powerful tools. Please get involved.

The simple truth is, if you have not been touched by this devastating and debilitating disease yet, consider yourself extremely lucky. Sadly, it's just a matter of time before it touches you. It is my hope that my actions today may prevent future generations from suffering with this disease. So give yourself piece of mind and do something today. I hope that what I am doing will allow me to leave this world knowing that I did everything possible to make that next generation have a fighting chance. There are no excuses for not wanting to help. The human cost factor is too high, and we are all accountable to do something.

There are many organizations out there like ADI and the Alzheimer's Association that can help you. The Alzheimer's Association got me started in many ways with my new journey. It not only helped me, but it also had helped my wife as my caregiver. They have a website with many resources at www.alz.org. I encourage you to reach out today if you have not already. I would also encourage you to educate yourself.

Please join me and Go Purple on Friday, Sept. 21 for World Alzheimer's Month. I wear a purple Alzheimer's bracelet every day. And for those living with Alzheimer's, stop focusing on what you cannot do and join me in the battle to advocate. We still have so much to give, and we need to use our skills at our own speed. There is nothing to be ashamed of. We are counting on all of you.

Over the past few years I have visited many websites that talk about Alzheimer's/dementia. The one thing that they all have in common is that not one of them encourages those of us who have the 
disease to continue to live and enjoy our lives. While I realize AD is a progressive and devastating disease we are still here, we are still alive, so treat us that way. Do not write us off.

I have always been savvy when it comes to finances and have always been a saver. One day I was speaking to a friend of mine who has $\mathrm{AD}$, and I was telling her how I did not want to spend a lot of the money I had saved, because I wanted to leave it for my wife for that rainy day. My friend told me: "This is the rainy day. What are you waiting for?" She was right, and that's exactly how I started to think

Just because we are living with $\mathrm{AD}$, does not mean we should curl up and think our life is over before it actually is. There is so much more we can still do to enjoy life. Make wonderful memories with your loved ones before the days turn ugly.

One thing I had always wanted was to own a convertible, so we purchased one. I wanted to drive it down to the Keys in Florida. I have a friend out in California who also has AD. She has an RV and had planned to travel around the country before she declined and was incapable of driving anymore. One day she mentioned that she was going to the Keys and I decided to meet up with her. I also wanted to go deep-sea fishing to catch a big game fish. Don't get me wrong I am not person who goes fishing, but it was something I have always wanted to do. I had looked into it and it was very pricy, but it has always been on my bucket list. I think we all have a list if we stop and think about it.

I had no real plans; I just wanted to go out and drive my convertible, to feel the fresh air and admire the beautiful scenery and enjoy nice weather. I had a great time. I had a permanent smile on my face. I decided to stay with my friend in the RV for a week and visit various campgrounds along the way. That was a whole new experience, and some of the places we stayed at had fabulous views.

It was great to be out on our own, not having to rely on caregivers all the time. We had some difficulties, but we were able to mange on our own. It cost me a few extra dollars along the way because when I purchased something I could not remember the price in order to be able to compare, and sometimes I took the wrong road and had to take the turnpike, but these were minor issues. This road trip made me feel so much better about me. It was good for my mind; I came back stronger because of what I had achieved.

This disease has a way of making you feel like you are no longer cable of doing things on your own. You lose your self-esteem and your self-confidence. After this trip I felt great. I did have to opportunity to go fishing. It was such a beautiful day with perfect conditions. The fish were not really biting to begin with but it didn't matter I was just happy to be on a boat again. Then I caught a fish that was about 10-12inches long. Then I caught a barracuda that was at least 18 inches long, and then one over two feet long. Not to long after that I got the big one, a king macro that was 42inches long! You should have seen the smile on my face. It is memories like this that we need to be making.

My friend in the RV has decided that she will not just use her mother's china and silverware on special occasions. Instead she took them with her in the RV. It gives her pleasure to use them every day. How many of you have a wonderful expensive hand bag or nice watch, which you only use on a special occasion?

Life is short; take pleasure in using those treasured items now. Start to create your own bucket list, don't just write it, DO IT! There are many wonderful memories that you can still make. Make them now before it's too late. Stop focusing on the negative. Make these last few years be the best of your life. You must do this now, before your mind no longer works.

Since being diagnosed with Young Onset Alzheimer's Disease I have dedicated much of my time to its advocacy. Over the years I have worked with many people in different parts of the world, and through my experience I have come to realize that a major problem in reaching a cure is our actions. The way we treat not only those who suffer from this disease but those who care for the afflicted, the focus on funding and research and the lack of communication and collective action. Although there are many brilliant people who are involved in Alzheimer's and Dementia action and research I feel that following some simple principals and plans we could bring about real change in the world of these diseases.

- PARTICIPATION-Patients, caregivers, family and friends must become advocates

- FUNDING-Unprecedented action from government and public sector is vital

- TEAM WORK-Organizations dedicated to fighting the cause must work together to reach a shared goal

- RESEARCH-It is imperative that professional medical research personnel work hand-in-hand with patients

- LIVE-Those suffering from the disease must learn to live happy and fulfilling lives

PARTICIPATION: The government wants to hear from us! I have been doing this a long time and I am told over and over again by government officials that they need to have a clear idea of the numbers of people with Alzheimer's so they can make the appropriate changes to policy etc. In order for the government to do something they need to see people with the disease. I know people have busy lives but if we want things to change, patients, caregivers and friends need to start taking action.

How can you help?: By getting involved! Write to the people who can help - government, health officials, and the press. But be mindful that you have to be persistent with these people, you have to fight. Can you imagine the impact if even a small percentage of the millions of sufferers took a little time to have their say?

Funding: We must look at other funding models for this disease. Unlike HIV and cancer, there are no survivors. Patients will continue to place a massive financial burden on the national economy; we need to be more proactive in how we fund research, care, medication and support for loved ones and caregivers.

How can you help?: By writing to Congress, and the National Institute of Health. These people are responsible for prioritizing the distribution of funds to critical diseases-Alzheimer's disease is not on the list; we need it on the list.

Team work: There are many organizations out there hosting their individual fund raising programs, which is to be commended but the downside to this is that they still insist on operating independently on one another. These people need to see the bigger picture, they need to set aside their politics and differences, and come together as one and work together - after all, they share the same goal don't they?

How can you help?: Well we can stop complaining about these organizations and give them solutions and guidance. Together we have the power to bring about change. Keep informed of all the latest news and action, don't listen to gossip or rumor-check the facts; do your homework. 
My name is Michael Ellenbogen. I am living with Alzheimer's disease. I spend almost every waking hour advocating for increased funding for research that will improve the treatment of this dreadful disease. In 2008, at the age of 49, I was diagnosed with Alzheimer's disease after struggling to get a diagnosis since my first symptoms began at age 39. There are more than five million Americans now suffering from this devastating disease.

The National Institutes of Health (NIH) funds research into critical and devastating diseases such as cancer and HIV/Aids. Yet there is much neglect and discrimination regarding the allocation of funds for research into Alzheimer's and related dementias. As a person who experiences the devastating impact of Alzheimer's disease every day I hope that research will lead eventually to postponing the onset or slow the progression of this disease, if not prevention and cure.

Currently, Alzheimer's disease only receives about $\$ 450$ million for research from $\mathrm{NIH}$, compared to more than $\$ 5$ billion for cancer and more than \$3billion for HIV/AIDS. I am astonished at the lack of funding dedicated to addressing the number one health epidemic. Historically, leadership from the federal government has helped lower the number of deaths from major diseases such as HIV/AIDS, heart disease, stroke and many types of cancers. This past experience provides hope that increased efforts directed at Alzheimer's disease will be met with similar success.

There are many more Americans living with Alzheimer's than HIV; more funding is desperately needed. If we do not act now this disease has the potential to bankrupt this country. Money allocated today will have an enormous return on investment if it leads to the kind of successes obtained for other diseases.

If you have not yet been touched by this devastating and debilitating disease it's just a matter of time. I hope that my advocacy will help prevent future generations having to suffer my fate and that of many others. You can help by increasing NIH funding for research on Alzheimer's disease and other dementias

I appeal to members of the House of Representatives, the Senate and the respective appropriations committees: Make the hard choices; increase funding for Alzheimer's disease. Do everything necessary to ensure that Alzheimer's disease gets the exposure, commitment and funding necessary to change the course of the disease before millions more Americans are affected.

My work as an advocate has provided opportunities to share my story on a national platform. I have provided public comment during meetings of the Advisory Council on Alzheimer's Research, Care and Services in addition to having my personal essay about overcoming the stigma of the disease featured in the Alzheimer's disease World Report 2012. I have also become a member of the Alzheimer's Association National Early-Stage Advisory Group, helping to raise awareness of the disease and provide insights on the most appropriate programs and services for individuals in the early stage of Alzheimer's and other dementias.

I hope that what I am doing now will allow me to leave this world knowing that I have done everything possible to make generations to come have a fighting chance. Do not forget these people or the future generations who will develop this disease. We face dying in the worst possible way.

As an Alzheimer's patient, I find it very difficult to perform tasks that I was once very capable of performing. Sometimes I am better than other times at doing the same task. People around me have accepted this fact and have tried to be very forgiving when I run into issues doing a task or when just trying to remember something. I really think that people around me should challenge me more at times.

For example, many of my doctors kept questioning me about whether or not I should still be driving. This of course was mentioned to my wife who also started wondering. I finally had a driving test a few years later. It was recommended that I no longer drive, even though I passed the test. I was almost borderline, but there was concern that I may not recognize when I become worse and could then become a danger. First of all, I have to tell you that the test they performed was not fair. I wonder how many regular people would be able to pass this test. The test also relied on me to learn new things in order to take the test. That is not fair since I have been driving the same vehicle all this time and nothing has changed. This constant talk about my driving has totally killed all of my self-esteem about driving. Every time I was in the car on the road with my wife, she constantly pointed out any mistakes I made, and her reaction time was much quicker than mine. I do realize I am a bit slower in my response time, but that is why I give myself more space between the other cars. Sometimes I am very far back or I just don't want to go around that slow car. There is nothing wrong with not feeling comfortable to go around that person. Let me do it at my speed.

I see many people on the road that I feel are so much worse than me and I wonder why they are still on the road, if I am supposedly so bad. I decided that I was going to drive to visit my daughter in South Carolina. I live in Jamison, PA in Bucks County. I was very scared to take this trip but I was trying to prove something to myself. It could have meant the end of my driving if I made a serious mistake along the way. I drove in one day, about 700miles, with the help of a GPS in my car. The more I drove, the more I was starting to feel comfortable behind the wheel. A few other people on the road made serious mistakes along the way and I easily avoided a possible accident. This trip was the best thing I could have done for myself. I now have almost all of my self-confidence back and my wife no longer makes constant comments about my driving, unless I have a real issue. I have now had two close calls that required quick thinking and maneuvering to avoid an accident. In both cases, I was able to avoid the issues without my wife's comments. Again it may have taken me an extra second or two to react, but I was fine.

\section{Coping strategies for daily challenges}

Because of this situation, I feel even stronger than ever that it is important to be challenged. I know it may be easier for you to do something for an Alzheimer's patient because it's much quicker for you to accomplish the task. But I really believe that if you take the time to coach us along the way, we may do better in the long run. Believe me, I know it's got to be very aggravating at times, but I really appreciate it. It takes a lot of patience on the part of the helper. Everyone is different and you need to know at what point in time you should not push. It's also hard to be patient and not raise your voice at the person you are trying to help, because it will only make it worse (Appendix 1).

A few months ago one of my friends mentioned that I am always talking about things related to Alzheimer's. While I know I spend my days advocating for this disease I did not realize I was that bad. Especially with those I am not trying to convince or influence. Although I appreciate the person telling me, it has really bothered me.

I started to give it some thought and tried to understand why and what I could do to change that. Not too long after that my wife made a similar comment, and that really hit home because their comments to me were so close together. 
I realized many things have contributed to this. The most important is I no longer work and I feel like I am locked in this house; I really have nothing else to do. I wish I could still be working and doing something meaningful, but unfortunately my skills required to perform those jobs are no longer there because of my Alzheimer's. I use to go to work, I used to talk with others about many different topics, not just work but everyday world issues.

I have tried to have similar conversations with people about issues in the news, and I don't always have the right information since I don't always understand it all, and only retain bits and pieces. While there was a time I was a news junkie, now I can rarely recall many of the topics or even can tie other stories together in my mind so I can speak intelligently. I have recently found myself starting discussions that go south because I start out with part of a subject, and when we delved into it deeper I was at loss for information. I felt stupid because I could no longer speak about something I once found very easy. I used to be great about talking about political issues which really requires you to know what you are talking about, but now I can barely defend my position, and I do worse for even bringing the subject up, and then I feel bad because I was not able to point out the real issues so the person could really make a true assessment.

Since I have no real job I have made it my mission to advocate for Alzheimer/dementia. I try to keep my mind as engaged as possible. I also try to focus on things that most don't, like the high hanging fruit which is probably not the best for some on like me. That involves dealing with many high-level people. While I do good at first I don't always have the answers they require, and sometimes may come across as not knowing what I am doing. It is very frustrating knowing that in my brain I have the answers, but I just do not know how to retrieve the information needed to help me do what I need to do. Especially when I need it the most, I may remember later on sometimes, but it's too late. There was a time that I could retrieve everything to my favor and keep track of everything one person would say to me.

Then I finally realized I listen to the weather report multiple times a day and I never seem to know what the weather is supposed to be like, which I always use to know. I just do not seem to retain it. I use to like reading the paper and I no longer do that because I have trouble retaining what I read or I don't remember how the story relates to something I read a few paragraphs back in the same article.

I used to have hobbies that I can no longer do because of the disease. I use to love boating and tinkering with electronics. I can no longer do any of these things. I rarely do anything around the house because I am afraid I will make it worse.

When I have conversations with others I do not always remember what we have spoken about in the past. I always hated it when you spoke to certain people and they keep repeating the same information you had spoken about in the past. I do not want to become one of them. There are so many discussions I want to have but I just can't because the lack of my ability and more. I miss that so much. To have an intelligent conversation with someone that can reply with meaningful information, where we both walked away with some new and interesting facts would be wonderful.

I was never one to blow my own horn, but I do that today so others can see some of the steps I have made in hopes that they feel they are willing to take risks and help me expand my mission. I have accomplished some great things and I think that is what I may share with my friends. Maybe I am repeating myself and I don't know it. I keep trying to figure out how I can change, but I struggle because I do not know what to do. It seems that Alzheimer's has taken over my life and not sure what or how to change.

\section{Acknowledgments}

None.

\section{Conflicts of interest}

Author declares there are no conflicts of interest.

\section{Funding}

None. 